\title{
Facile and Sensitive Determination of bisphenol A Based on MWCNTs-TiN Nanocomposites Modified Glassy Carbon Electrode
}

\author{
Jing-Yi Wang ${ }^{1}$, Jin-Wei Zhang ${ }^{1}$, Huan-Huan Xu ${ }^{2}$, Wei-Xin Lv ${ }^{2}$, Fen-Ying Kong ${ }^{2, *}$, Wei Wang ${ }^{2, *}$ \\ ${ }^{1}$ School of Chemistry and Chemical Engineering, Jiangsu University, Zhenjiang, China \\ ${ }^{2}$ School of Chemistry and Chemical Engineering, Yancheng Institute of Technology, Yancheng \\ 224051, China \\ *E-mail: kongfy@ycit.edu.cn, wangw@ycit.edu.cn
}

doi: $10.20964 / 2016.12 .52$

Received: 8 September 2016 / Accepted: 14 October 2016 / Published: 10 November 2016

\begin{abstract}
Herein, a novel and convenient electrochemical sensor based on a glassy carbon electrode modified with multi-walled carbon nanotubes-titanium nitride (MWCNTs-TiN) film for sensitive and efficient detection of bisphenol A (BPA) was developed. Several important parameters controlling the performance of the sensor, such as scan rate, the volume of MWCNTs-TiN dispersion and the $\mathrm{pH}$ value of buffer solution, were be investigated and optimized by cyclic voltammetry (CV) and differential pulse voltammetry (DPV). It was notable that the oxidation peak current of BPA had enhanced greatly and the oxidation overpotential had decreased significantly. Under the optimized conditions, the oxidation peak current was proportional to BPA concentration in the range of 0.1$50 \mu \mathrm{M}$, and the detection limit was $0.05 \mu \mathrm{M}$. Meanwhile, the modified electrode was also exhibited good reproducibility and stability, and was employed to in-situ determinate BPA in water samples with satisfying results.
\end{abstract}

Keywords: Bisphenol A; Voltammetric determination; Modified electrode; Multi-walled carbon nanotubes; Titanium nitride

\section{$\underline{\text { FULL TEXT }}$}

(C) 2016 The Authors. Published by ESG (www.electrochemsci.org). This article is an open access article distributed under the terms and conditions of the Creative Commons Attribution license (http://creativecommons.org/licenses/by/4.0/). 